\title{
Performance evaluation of the DNA methylation biomarker SHOX2 for the aid in diagnosis of lung cancer based on the analysis of bronchial aspirates
}

\author{
DIMO DIETRICH $^{1 *}$, CHRISTOPH KNEIP $^{2 *}$, OLAIDE RAJI $^{3}$, TRIANTAFILLOS LILOGLOU ${ }^{3}$, ANKE SEEGEBARTH $^{4}$, \\ THOMAS SCHLEGEL ${ }^{1}$, NADJA FLEMMING ${ }^{1}$, SEBASTIAN RAUSCH ${ }^{1}$, JÜRGEN DISTLER $^{1}$, \\ MICHAEL FLEISCHHACKER ${ }^{5}$, BERND SCHMIDT ${ }^{5}$, THOMAS GILES ${ }^{6}$, MARTIN WALSHAW $^{7}$, \\ CHRIS WARBURTON $^{8}$, VOLKER LIEBENBERG ${ }^{9}$ and JOHN K. FIELD ${ }^{3}$
}

\begin{abstract}
${ }^{1}$ Epigenomics AG, Berlin, Germany; ${ }^{2}$ Theracode GmbH, Mainz, Germany; ${ }^{3}$ Roy Castle Lung Cancer Research Programme, Department of Molecular and Clinical Cancer Medicine, University of Liverpool Cancer Research Centre, Liverpool L3 9TA, UK; ${ }^{4}$ Institute of Pathology, Charité University Hospital, Campus Benjamin Franklin, Berlin, Germany; ${ }^{5}$ University Hospital Halle (Saale), Internal Medicine I, Dept. Pneumology, Halle/Saale, Germany; ${ }^{6}$ Department of Pathology, Royal Liverpool Broadgreen University Hospital Trust, Prescot St. Liverpool, L7 8XP, UK; ${ }^{7}$ Respiratory Medicine, Royal Liverpool and Broadgreen University Hospital Trust, Thomas Drive, Liverpool, L14 3LB, UK; ${ }^{8}$ Thoracic Medicine - Aintree Chest Centre Aintree University Hospitals NHS Foundation Trust, Aintree House, University Hospital Aintree, Longmoor Lane, Liverpool, L9 7AL, UK; ${ }^{9}$ Metanomics Health GmbH, Berlin, Germany
\end{abstract}

Received September 14, 2011; Accepted October 14, 2011

DOI: 10.3892/ijo.2011.1264

\begin{abstract}
In the identification of subjects with lung cancer, increased DNA methylation of the SHOX2 gene locus in bronchial aspirates has previously been proven to be a clinically valuable biomarker. This is particularly true in cases where the cytological and histological results following bronchoscopy are undetermined. This previous case control study was conducted using research assay components and a complex work flow. To facilitate the use in a diagnostic setting, a CE marked in vitro diagnostic test kit to quantify SHOX2 DNA methylation in bronchial aspirates was developed and characterized. The presented assay for measuring SHOX2 DNA methylation in bronchial aspirates is based on two major steps: generation of bisulfite converted template DNA from patient samples followed by subsequent determination of $\mathrm{SHOX} 2$ biomarker methylation by real-time PCR. Individual kits for DNA preparation, real-time
\end{abstract}

Correspondence to: Dr John K. Field, Roy Castle Lung Cancer Research Programme, Department of Molecular and Clinical Cancer Medicine, University of Liverpool Cancer Research Centre, Liverpool L3 9TA, UK

E-mail: j.k.field@liv.ac.uk

Dr Dimo Dietrich, Epigenomics AG, Berlin, Germany

E-mail: dimo.dietrich@googlemail.com

*Contributed equally

Key words: lung cancer, SHOX2, DNA methylation biomarker, bronchial aspirate, diagnosis
PCR analysis and work flow control were developed. This study describes the analytical performance (reproducibility, accuracy, interfering substances, cross-reactivity) of the in vitro diagnostic (IVD) test kit 'Epi proLung BL Reflex Assay'. In addition, the intended use of the test was validated in a clinical performance evaluation (case control) study comprised of 250 patients (125 cases, 125 controls). The results describe the test as a robust and reliable diagnostic tool for identifying patients with lung cancer using Saccomanno-fixed bronchial lavage specimens (AUC [95\% confidence intervals] $=0.94$ [0.91-0.98], sensitivity 78\% [69-86]/specificity 96\% [90-99]). This test may be used as a diagnostic adjunct to existing clinical and pathological investigations in lung cancer.

\section{Introduction}

Lung cancer is responsible for more deaths than any other malignancy and is the second most common cancer in both men and women representing about $15 \%$ of all cancer diagnoses (1).

Currently, no screening for lung cancer has been implemented into clinical practice, therefore patients suspected of having lung cancer are diagnosed because of symptoms or secondarily to other clinical imaging investigations. A patient suspected of having lung cancer normally undergoes a full clinical workup which includes CT-scanning followed by bronchoscopy. At this time, bronchoscopy and the pathological assessment of tissue or cytological specimen obtained during the procedure, is the method of choice for the confirmation of the diagnosis of a suspected malignant lung disease.

In about half of the patients suspected of having lung cancer, the establishment of a final diagnosis after the first broncho- 
scopy fails (2), which triggers additional invasive diagnostic procedures. Even when there is a strong suspicion of lung cancer because of signs, symptoms and radiological findings, it often takes considerable effort and invasive procedures to obtain tissue samples, i.e., biopsies, to allow for the definitive confirmation of the presence of lung cancer.

DNA methylation plays an important role in regulating cellular differentiation and development (3) and aberrant methylation patterns comprise a major epigenetic feature of human cancers including lung (4-6). DNA methylation biomarkers in samples such as sputum and bronchial washings are now considered among the most important tools in lung cancer early detection research (7-9) while oral scrapes have also been suggested as a possible surrogate tissue for such screening purposes (10). A wide range of DNA methylation abnormalities in NSCLC tumors have been previously demonstrated (11-13).

The relative abundance of methylated SHOX2 gene copies in plasma is a sensitive and specific biomarker for lung cancer, in particular for SCLC and squamous cell carcinoma (14). Hypermethylation of the human homeobox gene SHOX2 (short stature homeobox 2) has previously been shown to be frequently accompanied by gene amplification (15). The positive performance of the $S H O X 2$ DNA methylation biomarker in plasma could be due to a correlation of DNA methylation and locus amplification in malignant cells (15). These accompanying effects render SHOX2 DNA methylation an attractive biomarker for malignant lung disease, particularly when sensitive detection is required (15).

DNA methylation of the SHOX2 gene locus has previously also been reported in a case control study with more than 500 patients (16) to be a sensitive and specific biomarker based on the analysis of bronchial fluids from patients with suspected lung cancer (16). Such a biomarker is clinically valuable, particularly when a final diagnosis cannot be established by histology or cytology after the first bronchoscopy. A diagnostic test with a high specificity can reduce the need for further costly and invasive procedures and therefore minimize the time until treatment can begin. The previous case control study was conducted using research assay components. To facilitate the use in a diagnostic setting, an in vitro diagnostic test kit, the Epi proLung BL Reflex Assay was developed and validated for CE-marking through the experiments described herein. Analytical performance is described by means of cut-off verification, accuracy, daily-use reproducibility, interfering substances and cross reactivity. Clinical performance is evaluated in a case control study using specimens from 250 patients ( 125 controls, 125 cases) who were investigated for suspected lung cancer. The results indicate that this new test allows for accurate detection of SHOX2 DNA methylation in bronchial lavage specimens.

\section{Materials and methods}

Patients, specimens, and model samples

Patients and sampling procedure. This study was performed with informed consent (written) and approved by the North West 2 Research Ethics Committee (Liverpool Central).

All patients donating samples for this study were investigated for suspected lung cancer. All bronchial lavage samples were collected during bronchoscopy by aspiration with a flexible bronchoscope from the region of the suspicious lesion after injecting 10-20 $\mathrm{ml}$ of isotonic saline solution and prior to starting any cancer specific treatment, if applicable. Specimen were fixed with equal volume of Saccomanno's fixative and stored at room temperature for up to 12 years.

Establishment of methylation cut-off for patient stratification study. Left-over bronchial lavage samples from six selected patients analyzed in a previous study (16) was used in order to transfer the clinical decision point to the test kit. The median methylation of these patient samples represented the cut-off of the previous study.

Clinical performance evaluation study. Bronchial lavage samples from 250 patients ( 125 cases, 125 controls) used for clinical validation were collected in the course of the Liverpool Lung Project Research Program (17) (University of Liverpool Cancer Research Centre, Liverpool, UK).

Table I describes the detailed characteristics of the patient population. The diagnosis of lung cancer was confirmed by cytology and/or histology from biopsy or surgical resection specimen. Patients suspected of having lung cancer who underwent a workup in the same hospitals and at the same time period but who did not show any evidence of malignant lung disease and had a minimum cancer free survival of one year were considered as the control group.

Analytical performance, sample quality control and sample validity. Bronchial lavage samples for characterizing the analytical performance of the test were provided by the Charité University Hospital (Berlin, Germany). These samples were used solely for analyzing the analytical performance of the test. Therefore, a final diagnosis was not required. Eighty-four individual samples were analyzed to determine the number of valid results which can be obtained from freshly prepared samples. In addition, three model bronchial lavage samples (A-C) were prepared by pooling these individual samples in order to obtain sufficient material to test the analytical performance of the assay. The content of methylated SHOX2 DNA in these model bronchial lavage samples was adjusted by spiking HeLa cells which were shown to be methylated at the SHOX2 locus (data not shown).

Model DNAs with defined methylation levels. DNA from peripheral blood lymphocytes (PBL) and universal methylated DNA (Millipore, Billerica, MA) were mixed to produce model DNA samples with defined levels $(0.1,0.8$, and $1.6 \%)$ of methylated target and unmethylated background DNA. The DNA concentration of PBL and universal methylated DNA was determined by UV spectrophotometry using a Nanodrop ND-1000 spectral photometer (Nanodrop Technologies, Wilmington, DE, USA).

Determination of SHOX2 DNA methylation levels in bronchial lavage samples using the Epi proLung BL Reflex Assay

Test principle. The CE marked in vitro diagnostic test Epi proLung BL Reflex Assay is comprised of the three individual kits Epi proLung BL DNA Preparation Kit for the preparation of bisulfite converted DNA using ammonium bisulfite chemistry (15), the Epi proLung BL real-time PCR Kit for quantitative and sensitive determination of $S H O X 2$ DNA 
Table I. Characteristics of the patient population. ${ }^{\mathrm{a}}$

$\begin{array}{ccc}\text { Total } & \frac{\text { Cases }}{125(100 \%)} & \frac{\text { Controls }}{125(100 \%)}\end{array}$

\begin{tabular}{|c|c|c|c|}
\hline \multicolumn{4}{|l|}{ Age (years) } \\
\hline$\leq 50$ & $9(4 \%)$ & $3(2 \%)$ & $6 \quad(5 \%)$ \\
\hline $51-60$ & $55(22 \%)$ & $20(16 \%)$ & $35(28 \%)$ \\
\hline$>60$ & $186(74 \%)$ & $102(82 \%)$ & $84(67 \%)$ \\
\hline Median age & 66 & 67 & 65 \\
\hline Age range & $45-86$ & $46-85$ & $45-86$ \\
\hline \multicolumn{4}{|l|}{ Smoking habits } \\
\hline Non-smokers & $27(11 \%)$ & $2(2 \%)$ & $25(20 \%)$ \\
\hline Smokers (current and former) & $221(88 \%)$ & $123(98 \%)$ & $98(78 \%)$ \\
\hline Unknown smoking status & $2(1 \%)$ & $0 \quad(0 \%)$ & $2(2 \%)$ \\
\hline Range packs/years (smokers only) & $2-252$ & $4-252$ & $2-92$ \\
\hline Median packs/years (smokers only) & 41 & 47 & 32 \\
\hline Mean packs/years (smokers only) & 45 & 53 & 34 \\
\hline \multicolumn{4}{|l|}{ Gender } \\
\hline Female & $117(47 \%)$ & $53(42 \%)$ & $64(51 \%)$ \\
\hline Male & $133(53 \%)$ & $72(58 \%)$ & $61(49 \%)$ \\
\hline \multicolumn{4}{|l|}{ Histology subtype } \\
\hline NSCLC (squamous cell carcinoma) & $\mathrm{X}$ & $28(22 \%)$ & $\mathrm{x}$ \\
\hline NSCLC (adenocarcinoma) & $\mathrm{x}$ & $26(21 \%)$ & $\mathrm{x}$ \\
\hline NSCLC (NOS) & $\mathrm{x}$ & $9(7 \%)$ & $\mathrm{x}$ \\
\hline SCLC & $\mathrm{x}$ & $40(32 \%)$ & $\mathrm{x}$ \\
\hline Carcinoma & $\mathrm{x}$ & $16(12 \%)$ & $\mathrm{x}$ \\
\hline Large cell carcinoma & $\mathrm{x}$ & $2(2 \%)$ & $\mathrm{x}$ \\
\hline Carcinoid & $\mathrm{x}$ & $3(2 \%)$ & $\mathrm{x}$ \\
\hline Malignant neoplasm & $\mathrm{x}$ & $1(1 \%)$ & $\mathrm{x}$ \\
\hline \multicolumn{4}{|l|}{ Cytology result } \\
\hline Positive & $45(18 \%)$ & $45(36 \%)$ & $0 \quad(0 \%)$ \\
\hline Negative & $181(72 \%)$ & $65(52 \%)$ & $116(93 \%)$ \\
\hline Suspicious & $18(7 \%)$ & $14(11 \%)$ & $4(3 \%)$ \\
\hline Unknown & $6(2 \%)$ & $1(1 \%)$ & $5(4 \%)$ \\
\hline
\end{tabular}

${ }^{a}$ Clinical data of the 250 patient samples (125 cases, 125 controls) included into the clinical validation study.

methylation, and the Epi proLung BL Work Flow Control Kit for controlling the whole work flow.

The Epi proLung BL DNA Preparation Kit was optimized for the lysis of cellular material from $2 \mathrm{ml}$ Saccomanno-fixed bronchial lavage samples followed by bisulfite-conversion of DNA contained in the lysate. After a final purification step, the DNA is suited for the analysis of the methylation status by real-time PCR amplification using the Epi proLung BL real-time PCR Kit. This real-time PCR kit combines HeavyMethyl $^{\mathrm{TM}}$ (18) (Fig. 1) and TaqMan ${ }^{\circledR}$ technologies together with the $\Delta \Delta \mathrm{CT}$ method $(19,20)$ for the determination of the relative amount of methylated $S H O X 2$. Real-time PCR is a duplex reaction for the simultaneous detection of two independent targets in a single tube. One target which serves as a reference measurement is a methylation-unspecific PCR for quantification of total input DNA based on the actin- $\beta$ $(A C T B)$ gene. The PCR for assaying the DNA methylation of SHOX2 is a methylation-specific HeavyMethyl ${ }^{\mathrm{TM}} \mathrm{PCR}$. The HeavyMethyl $^{\mathrm{TM}}$ technology (Fig. 1) is based on amplification of bisulfite converted DNA using methylation unspecific 

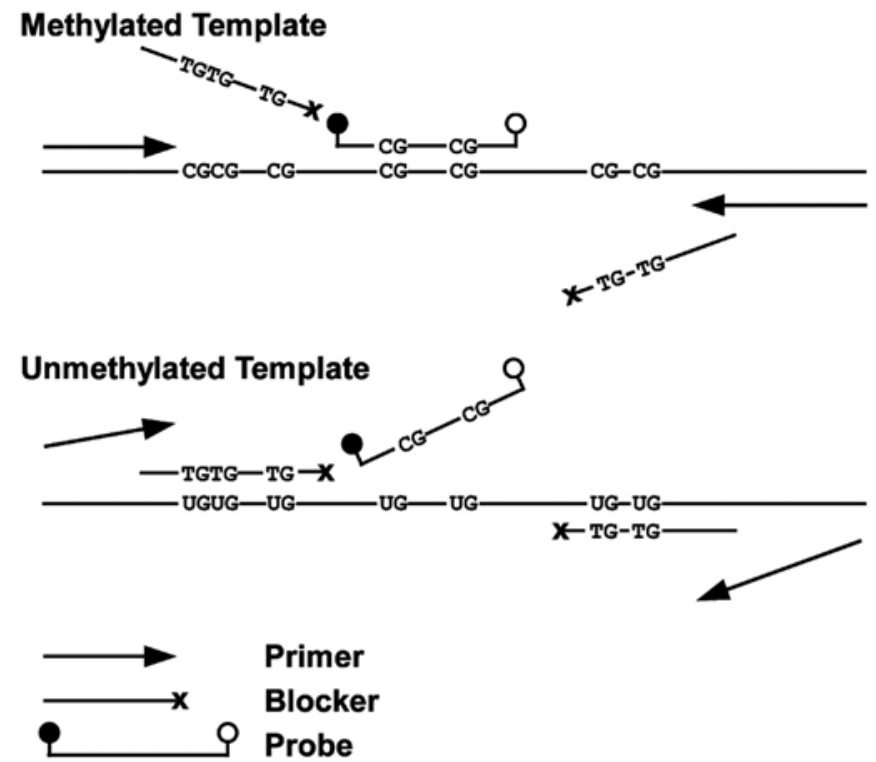

Figure 1. HeavyMethyl ${ }^{\mathrm{TM}}$ real-time PCR technology in principal. Blocker oligonucleotides bind specifically to bisulfite converted unmethylated DNA, therefore preventing primers from binding to the same template. A TaqMan ${ }^{\circledR}$ probe allows for the specific detection of the PCR product derived from bisulfite converted methylated DNA.

primers in combination with methylation specific blocking oligonucleotides, thereby enabling the sensitive and specific amplification of methylated DNA (18). Detection of amplification is performed using TaqMan ${ }^{\circledR}$ probes. The Epi proLung BL Calibrator contained in the real-time PCR kit is used for the calculation of a relative methylation value according to the $\Delta \Delta C T$ method $(19,20)$. This calibrator is also used to stabilize the test results with regard to inter-plate, inter-instrument, inter-operator and daily-use variability.

The Epi proLung BL Work Flow Control Kit contains positive and negative control material to be used when processing Saccomanno-fixed bronchial lavage fluid through a procedure of DNA preparation, amplification and detection.

Preparation of bisulfite DNA. Bisulfite DNA from Saccomannofixed bronchial lavage samples was prepared following the instructions for use (IFU) from the Epi proLung BL DNA Preparation Kit (Epigenomics AG, Berlin, Germany). Samples from the clinical validation study were randomized and processed in batches comprised of six patient samples and one Epi proLung BL Work Flow Positive Control and one Epi proLung BL Work Flow Negative Control each. The work flow controls were used strictly following the IFU from the Epi proLung BL Work Flow Control Kit (Epigenomics AG, Berlin, Germany).

For the preparation of bisulfite DNA from model DNAs using the Epi proLung BL DNA Preparation Kit, the DNA was directly subjected to the bisulfite reaction without prior DTT and proteinase $\mathrm{K}$ treatment.

Real-time PCR analysis. DNA methylation of the SHOX2 gene was quantified on an AB 7500 Fast Real-Time PCR System (Applied Biosystems, CA, USA) using the Epi proLung BL real- time PCR Kit following the respective protocol in the instructions for use.

\section{Results}

\section{Analytical performance}

Reproducibility and accuracy. Reproducibility of the test kit was evaluated by analyzing three different model bronchial lavage samples (pooled individual samples, A-C) and three model DNAs (different mixtures of methylated [0.1, 0.8 and $1.6 \%$ ] in unmethylated DNA). Batches with eight determinations (three model DNAs and three pooled lavage samples, one Positive and one Negative Control from the Epi proLung BL Work Flow Control Kit) were run through the whole work flow. Altogether, 27 such batches were run through three different operators on different days. Each operator used three different reagent (kit) lots and three different PCR instruments for analysis. Additionally, different types of instrument software were used to evaluate any software based effects on raw data and test results. To assess reproducibility, mean $\Delta \Delta \mathrm{CT}, \mathrm{SD}$, $\% \mathrm{CV}$ and ANOVA p-values were calculated.

As shown in Fig. 2 and Table II, the assay provided highly reproducible results when samples were processed and analyzed in different batches/runs, by different operators, on different instruments and using different reagent (kit) lots. In some cases, different operators, instruments or runs revealed to be significant sources of result variability, as indicated by $p<0.05$. However, overall variability of tested samples was low except for model lavage sample A, which was the sample with the lowest relative amount of methylated SHOX2. As this low concentrated sample resulted in $\triangle \Delta C T$ values far above the clinical cut-off (definition of the clinical cut-off is described in section 'Clinical performance'), the final test result (test negative) was not affected by the increase of variability compared to higher concentrated samples. With regard to the final test results based on dichotomization at the cut-off ( $\triangle \Delta C T$ T 9.5 as determined below), all determinations from same samples led to concordant test results (model lavage sample A and $0.1 \%$ methylated model DNA: test negative; model lavage sample B and C, 0.8 and 1.6\% methylated model DNAs: test positive), irrespective of different test variables, i.e., operators, instruments, software, kit lots (Fig. 2).

Interfering substances and cross reactivity. Cross-reactivity of the test kit was evaluated by analyzing spiked controls from Epi proLung BLWork Flow Control Kit with DNA from bacteria that are commonly found in the respiratory tract of patients with lung disease $(21,22)$. The following organisms were tested and had no effect on test performance (data not shown): Mycobacterium sp., Haemophilus influenzae, Streptococcus pneumoniae, Pseudomonas aeruginosa, Chlamidophila pneumoniae.

Performance of the test kit was evaluated in the presence of different interfering substances. For this purpose two independent model lavage samples were spiked with potential interfering substances frequently present in the lung of patients with symptoms of respiratory disease. The following substances were tested and had no effect on test performance (data not shown): hemoglobin $(50 \mu \mathrm{g} / \mathrm{ml})$, glucocorticoid $(300 \mu \mathrm{g} / \mathrm{l})$, salbutamolsulfate $(400 \mu \mathrm{g} / \mathrm{l})$, 


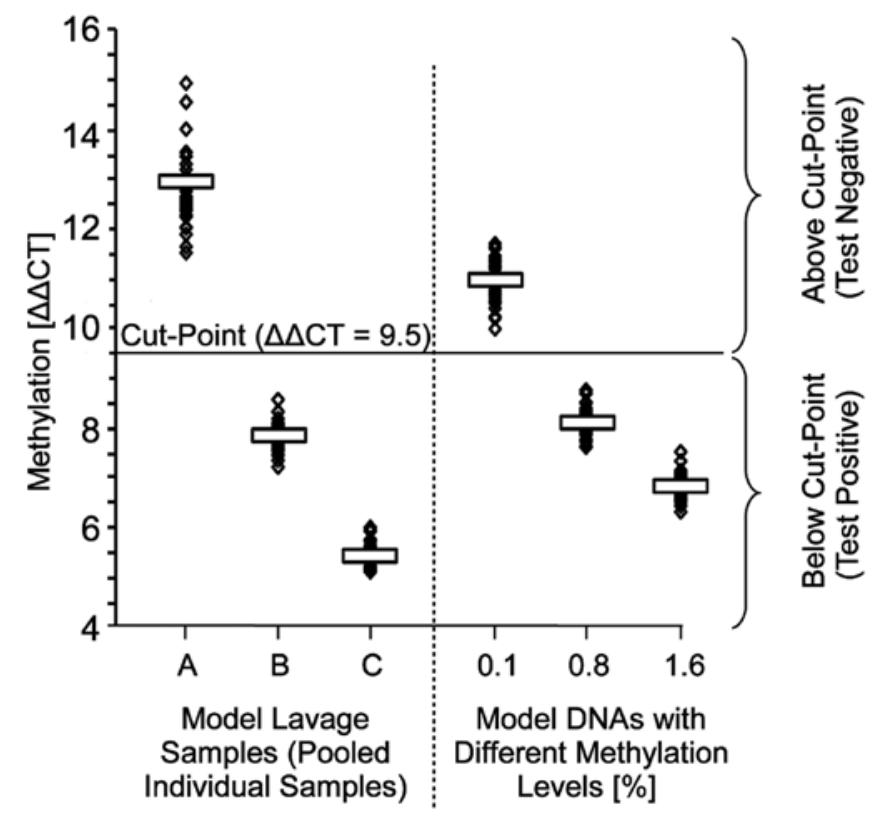

Figure 2. Reproducibility of Epi proLung BL Reflex Assay. Reproducibility of the Epi proLung BL Reflex Assay was evaluated by analyzing three model lavage samples (pooled Saccomanno-fixed bronchial lavage specimens (pools A-C]) and three different methylated model DNAs (0.1, 0.8 and $1.6 \%$ methylated). Two out of the three model lavage samples and two out of three model DNA mixtures where below the cut-point (test positive), one was above the cut-point (test-negative). The samples were analyzed by three different operators on different days using three different reagent (kit) lots and three different PCR instruments in order to introduce the highest possible variability into the test results.

unconverted genomic DNA (1 $\mu \mathrm{g})$, tobacco smoke condensate and mucin $(2.5 \mu \mathrm{g} / \mathrm{ml})$.

\section{Clinical performance}

Overview. Bronchial lavage specimens were analyzed in the course of three individual studies in order to establish a clinical cut-off for patient stratification and to show the clinical performance of the test kit.

Establishment of methylation cut-off for patient stratification: Six selected samples from a previous study (16) have been analyzed in order to map the methylation cut-off from a previous study onto the Epi proLung BL Reflex Assay. The selected samples showed methylation levels close to the methylation cut-off ( 3 samples above and 3 samples were below the cut-off) from the previous study (16).

Sample quality control and sample validity: Eighty-four freshly prepared Saccomanno-fixed samples were analyzed to show how many valid results according to the instruction for use of the Epi proLung BL DNA Preparation Kit can be expected from freshly prepared samples as analyzed in the clinical routine.

Clinical performance evaluation: The intended use of the test kit was validated in a retrospective case control study comprised of Saccomanno-fixed bronchial lavage samples from 250 patients (125 cases and 125 controls).

Establishment of methylation cut-off for patient stratification. SHOX2 methylation has been reported to be a suited lung cancer biomarker in bronchial aspirates (16). In this study, it has also been shown that low level background methylation was found even in samples from patients without lung cancer. This requires a specific methylation value as a clinical decision point (cut-off) in order to identify patients with high risk of having lung cancer (false-positives $\leq 5 \%$ ). The decision point of the assay has been defined by means of cut-off optimization on the clinical study previously described (16). To establish the cut-off for the test kit, left-over material from a set of six patients was selected which best represent the methylation level at the cut-off. The median methylation level of these patients $\left(\Delta \Delta \mathrm{CT}_{\text {Cut-Off }}=9.5\right)$ was determined using the Epi proLung BL Reflex Assay and established as a clinical decision point for the assay. According to this clinical cut-off, samples with $\Delta \Delta \mathrm{CT}$ values $<9.5$ are rated as test positive while samples with $\Delta \Delta \mathrm{CT}$ values $>9.5$ are rated as test negative based on the IFU procedure.

Sample quality control and sample validity. The Epi proLung BL DNA Preparation Kit is used for bisulfite conversion and subsequent purification of cellular DNA from $2 \mathrm{ml}$ Saccomannofixed bronchial lavage. Only samples which yielded a minimum nucleic acid amount are suitable for result interpretation after real-time PCR analysis, as too low DNA concentrations can lead to high variability. The total amount of bisulfite converted DNA purified from individual samples is analyzed via the $A C T B$ reference assay and is represented by its CT value. According

Table II. Summary statistics of bronchial lavage model samples (pools A-C) and model DNAs (mixtures of artificially methylated DNA and DNA from PBL) analyzed in course of the reproducibility analysis.

\begin{tabular}{lcccccc}
\hline & Pool A & Pool B & Pool C & $\begin{array}{c}0.1 \% \text { methylated } \\
\text { model DNA }\end{array}$ & $\begin{array}{c}0.8 \% \text { methylated } \\
\text { model DNA }\end{array}$ & $\begin{array}{c}1.6 \% \text { methylated } \\
\text { model DNA }\end{array}$ \\
\hline Mean $\Delta$ CCT & 13.02 & 7.86 & 5.48 & 10.98 & 8.15 & 6.85 \\
SD & 1.44 & 0.29 & 0.25 & 0.45 & 0.30 & 3.68 \\
\%CV & 11.06 & 3.69 & 4.56 & 4.10 & 0.1704 & 3.94 \\
Inter-instrument (p-value) & $0.0484^{\mathrm{a}}$ & 0.1260 & $0.0015^{\mathrm{a}}$ & 0.6324 & 0.4138 & 0.1523 \\
Inter-operator (p-value) & $0.0073^{\mathrm{a}}$ & 0.8625 & 0.3888 & 0.7169 & $0.0298^{\mathrm{a}}$ & 0.4133 \\
Inter-run (p-value) & 0.1271 & 0.0567 & $0.0003^{\mathrm{a}}$ & $0.0472^{\mathrm{a}}$ & 0.0528 \\
\hline
\end{tabular}

${ }^{a}$ If ANOVA $\mathrm{p}<0.05$, then different operators, instruments or runs were a significant sources of result variability. 
Table III. Clinical performance. ${ }^{\mathrm{a}}$

\begin{tabular}{lrccccc}
\hline Histology & Total & Valid measurements & Test-positive & Test-negative & Sensitivity & Specificity \\
\hline All cases & 125 & 100 & 78 & 22 & $78 \%$ & $\mathrm{x}$ \\
NSCLC (squamous cell carcinoma) & 28 & 23 & 21 & 2 & $91 \%$ & $\mathrm{x}$ \\
NSCLC (adenocarcinoma) & 26 & 22 & 17 & 5 & $77 \%$ & $\mathrm{x}$ \\
NSCLC (NOS) & 9 & 9 & 7 & 2 & $78 \%$ & $\mathrm{x}$ \\
SCLC & 40 & 30 & 28 & 2 & $93 \%$ & $\mathrm{x}$ \\
Carcinoma & 16 & 11 & 4 & 7 & $36 \%$ & $\mathrm{x}$ \\
Large cell carcinoma & 2 & 1 & 0 & 1 & $0 \%$ & $\mathrm{x}$ \\
Carcinoid & 3 & 3 & 1 & 2 & $33 \%$ & $\mathrm{x}$ \\
Malignant neoplasm & 1 & 1 & 0 & 1 & $0 \%$ & $\mathrm{x}$ \\
Controls & 125 & 104 & 4 & 100 & $4 \%$ & $96 \%$ \\
\hline
\end{tabular}

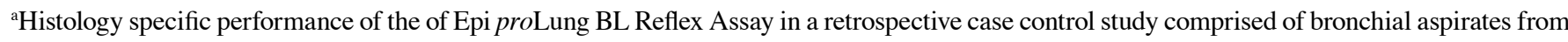
patients with suspected lung cancer. In total, 250 aspirates (125 controls, 125 cases) were analyzed. Valid results were obtained from 204 samples (104 controls, 100 cases).

to the instructions for use, only samples with $A C T B$-CT values (median of triplicate measurement) $<29$ are allowed for result interpretation. Samples showing higher $A C T B$-CT values are excluded from analysis because their DNA yield was too low. In the clinical performance evaluation study archived samples, stored for up to 12 years were used. This retrospective study design was required since follow-up data from control patients was needed to ensure that they remained lung cancer-free for at least 12 months after bronchoscopy in the Liverpool Lung Project Research Program (17) case-control data set under investigation. The long-term storage of the samples led to a loss of DNA and therefore higher ACTB-CTs. The 250 samples analyzed in the course of the clinical performance evaluation study as describe below resulted on average in an $A C T B-C T$ of 28.4. The $A C T B-C T$ strongly correlated with the age of the sample (Spearman's correlation, $\mathrm{p}<0.0001$ ). Therefore, a higher number of invalid results from archived samples occurred as compared to freshly prepared samples, when the criterion of $A C T B-\mathrm{CT} \leq 29$ is applied.

Sample validity applying the $A C T B-C T \leq 29$ criterion was determined using 84 freshly prepared Saccomanno-fixed samples. In the freshly prepared sample set, 4 out of the 84 (5\%) did not contain a cellular fraction after centrifugation and were excluded from further analysis. From the remaining 80 samples valid results $(A C T B-C \mathrm{~T} \leq 29)$ were obtained from 74 (93\%) when analyzed with Epi proLung BL real-time PCR Kit.

Clinical performance evaluation. The intended use of the test kit was validated in a case control study comprised of 250 patients (125 cases and 125 controls). Saccomanno-fixed bronchial lavage samples from all study subjects were investigated for suspected lung cancer. The samples were processed by three different operators on different days using three different realtime PCR instruments and kit lots. Valid results according to the instructions for use $(A C T B-C \mathrm{~T} \leq 29)$ were obtained from 154 samples ( 79 controls, 75 cases). The assay allowed for the detection of $81 \%(95 \%$ CI $71-89 \%)$ of lung cancer patients at
95\% (95\% CI 88-99\%) specificity. Due to the age of the samples, a significant number of bronchial lavage samples $(n=96)$ showed an $A C T B$-CT $>29$ which according the instruction for use established for freshly prepared samples (as expected to be used in clinical routine) indicated an invalid sample. However, in order to increase the number of valid sample measurements in the clinical performance evaluation study, the $A C T B-C T \leq 29$ criterion for qualifying samples was set to $A C T B-C T \leq 31.5$ and the performance recalculated for archived samples in this retrospective study only. Table III displays a summary of data from the clinical performance evaluation. With the modified ACTB-CT cut-off $\leq 31.5,204$ of 250 samples $(82 \%)$ were qualified as valid, even though the samples were stored for up to 12 years. Out of the 204 valid samples, 100 samples were from cancer patients and 104 samples were from patients with benign lung disease (controls). No significant correlation between sample validity and any clinicopathological parameter and patient data was found. Out of 100 valid cancer patient samples, 78 samples showed $\Delta \Delta \mathrm{CT}$ values below the cut-off value of 9.5 and were therefore classified as test-positive. Overall clinical sensitivity estimate for the modified cut-off therefore equals $78 \%$ (95\% CI $69-86 \%$ ). Out of 104 valid controls, 100 samples showed $\Delta \Delta C T$ values above the cut-off of 9.5 and were therefore classified as test-negative. Overall clinical specificity estimate therefore equals $96 \%$ (95\% CI 90-99\%). Fig. 3B displays the ROC curve of the assay which resulted in an AUC of 0.94 (95\% CI 91-98\%). Sensitivity and specificity of the assay independent of a cut-off are shown in Fig. 3. A higher SHOX2 DNA methylation (lower $\triangle \triangle \mathrm{CTs}$ ) can be found in bronchial aspirates from cases in comparison to the controls (Fig. 3A). The measured methylation in the whole population ranged from $\Delta \Delta \mathrm{CT}=-0.22$ to $\Delta \Delta \mathrm{CT}=$ 20.37 (Fig. 3A) shows that false-positive results (controls below the cut-off $\Delta \Delta \mathrm{CT}=9.5$ ) can only be found in controls which are close to the cut-off. The probability of patients having cancer increases with higher DNA methylation (lower $\triangle \mathrm{CCT}$ ) resulting in a higher specificity. No false-positives can be found for patients with a $\Delta \Delta \mathrm{CT}$ below approximately 6 resulting in $100 \%$ specificity. Therefore, the specificity of the test can be increased 
A

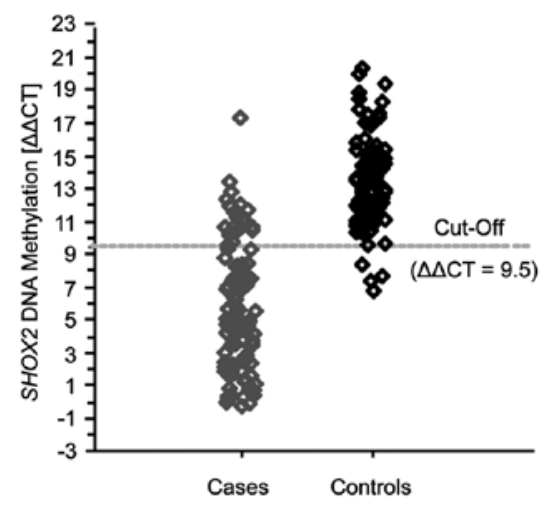

B

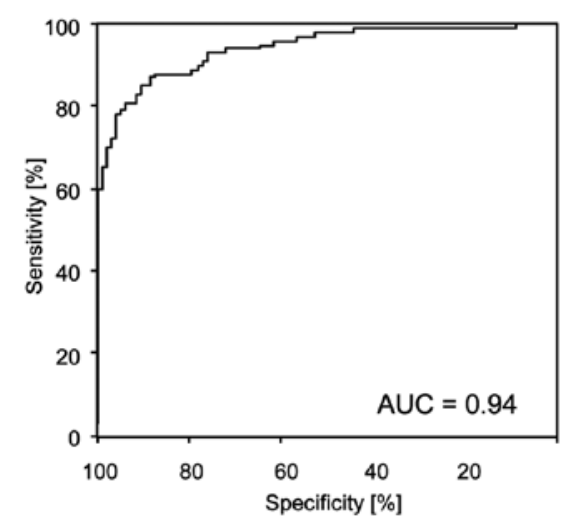

\section{C}

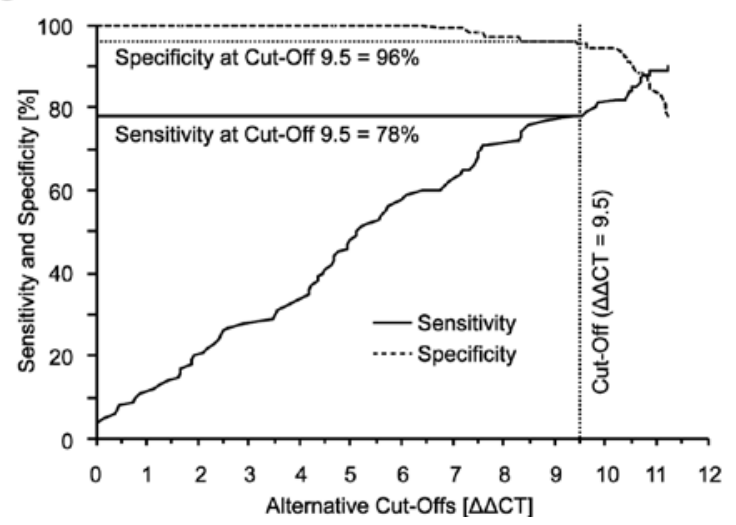

Figure 3. Results of the clinical performance evaluation study. (A) SHOX2 DNA methylation values measured in cases (grey) and controls (black). Low $\triangle \triangle C T$ indicate a high SHOX2 DNA methylation. (B) Receiver operating characteristic (ROC) and the resulting area under the curve (AUC). (C) Resulting sensitivity and specificity of the Epi proLung BL Reflex Assay when using alternative cut-offs for patient stratification. No false positive results can be found for patients with a $\Delta \Delta \mathrm{CT}$ below approx. 6 resulting in $100 \%$ specificity.

Table IV. Clinical performance of Epi proLung BL Reflex Assay with regard to cytology (only valid samples according to Table III) in a retrospective case control study comprised of 250 patient samples.

\begin{tabular}{lcccc}
\hline $\begin{array}{l}\text { Cytology } \\
\text { result }\end{array}$ & $\begin{array}{c}\text { Cases } \\
\text { total }\end{array}$ & $\begin{array}{c}\text { Controls } \\
\text { total }\end{array}$ & $\begin{array}{c}\text { Test-positive cases } \\
\text { [sensitivity (\%)] }\end{array}$ & $\begin{array}{c}\text { Test-negative controls } \\
\text { [specificity }(\%)]\end{array}$ \\
\hline All & 100 & 104 & $78(78 \%)$ & $96(96 \%)$ \\
Unknown & 1 & 4 & $1(100 \%)$ & $4(100 \%)$ \\
Negative & 48 & 96 & $30(63 \%)$ & $92(96 \%)$ \\
Suspicious & 14 & 4 & $12(86 \%)$ & $4(100 \%)$ \\
Positive & 37 & 0 & $35(95 \%)$ & - \\
\hline
\end{tabular}

by using alternative cut-offs. Fig. 3 right shows the sensitivity and specificity in relation to alternative $\triangle \triangle C T$ values as cut-offs. The specificity increased while the sensitivity decreased when using lower $\triangle \triangle C T$ values as cut-offs.

The clinical performance with regard to the cytological results is shown in Table IV. Even among the samples with cytological negative results the test detected $63 \%$ of all cases. The number of detected cases is higher in the group of patients with positive or suspicious cytological results $(95 \%$ and $86 \%$, respectively).

\section{Discussion}

Lung cancer is a devastating disease and represents a major public health problem (1). Patients suspected of having lung cancer usually seek medical attention because of symptoms or are diagnosed accidentally through imaging methods which are done for other indications. These patients are normally further investigated by a CT scan of the thorax followed by bronchoscopy. Cytological and histological specimens, such as biopsies and/or bronchial lavages, obtained during the bronchoscopy are used to confirm the diagnosis by the pathologist or cytologist. The CE marked in vitro diagnostic (IVD) test 'Epi proLung BL Reflex Assay' has been developed in order to allow for the confirmation of the presence of lung cancer based on analysis of bronchial lavage samples even when cytology results are negative or suspicious.

The test measures DNA methylation of the SHOX2 gene. Aberrant DNA methylation plays a major role in carcinogenesis $(4,6,23,24)$. The SHOX2 gene is hypermethylated and 
frequently amplified in tumors of the lungs (15). These accompanying effects qualify this biomarker for the diagnosis of lung cancer, especially when sensitive detection is needed, i.e. in plasma (14). The relative abundance of methylated SHOX2 gene copies in bronchial aspirates obtained during bronchoscopy are found to correlate with the presence of lung cancer (16). The determination of the relative amount of methylated SHOX2 is possible after extraction, conversion with ammonium bisulfite (15) and purification of DNA from bronchial fluid specimens (15). The Epi proLung BL real-time PCR Kit detects the relative amount of methylated SHOX2 gene fragments in a background of normal DNA in a real-time PCR assay based on TaqMan technology.

The results from the analytical performance indicate this test kit as a robust and reliable diagnostic test. Its ease to handle, the short time to result $(<8 \mathrm{~h})$ and the requirement of only standard laboratory equipment (i.e., centrifuge, thermomixer and $\mathrm{AB}$ 7500 Fast Real-Time PCR System) allows for a smooth implementation of the test into the clinical routine. The intended use has successfully been validated in a case study, showing that the presence of lung cancer could be confirmed in $78 \%$ of cancer patients at a low false-positive rate (4\%).

In conclusion, the methylation analysis of SHOX2 has been successfully validated to be a valuable biomarker for highly specific and sensitive lung cancer diagnosis. The assay is highly reproducible and did not show any interference with lung pathogens or substances commonly found in the respiratory tract of patients undergoing bronchoscopy. The test, which now bears a CE mark, may be used as an aid in the diagnosis of a malignant lung disease adjunct to other diagnostic procedures and support the decision process of clinicians in the workup of patients suspected to have lung cancer.

\section{Acknowledgments}

The authors thank Dr P. Braun (Max Planck Institute for Infection Biology, Berlin) for providing HeLa cells. This study was performed as the performance evaluation study required for CE marking of the Epi proLung BL Reflex Assay in compliance with the European Directive on in vitro diagnostic medical devices (98/79/EC) (25).

\section{References}

1. Jemal A, Siegel R, Ward E, Hao Y, Xu J and Thun MJ: Cancer statistics, 2009. CA Cancer J Clin 59: 225-249, 2009.

2. Roth K, Hardie JA,Andreassen AH, Leh F and Eagan TM: Predictors of diagnostic yield in bronchoscopy: a retrospective cohort study comparing different combinations of sampling techniques. BMC Pulm Med 8: 2, 2008.

3. Callinan PA and Feinberg AP: The emerging science of epigenomics. Hum Mol Genet 15 Spec No 1: R95-101, 2006.

4. Esteller M: Epigenetic gene silencing in cancer: the DNA hypermethylome. Hum Mol Genet 16 Spec No 1: R50-59, 2007.

5. Belinsky SA: Gene-promoter hypermethylation as a biomarker in lung cancer. Nat Rev Cancer 4: 707-717, 2004.

6. Esteller M: Cancer epigenomics: DNA methylomes and histonemodification maps. Nat Rev Genet 8: 286-298, 2007.

7. Machida EO, Brock MV, Hooker CM, Nakayama J, Ishida A, Amano J, Picchi MA, Belinsky SA, Herman JG, Taniguchi S and Baylin SB: Hypermethylation of ASC/TMS1 is a sputum marker for late-stage lung cancer. Cancer Res 66: 6210-6218, 2006.
8. Belinsky SA, Liechty KC, Gentry FD, Wolf HJ, Rogers J, Vu K, Haney J, Kennedy TC, Hirsch FR, Miller Y, Franklin WA, Herman JG, Baylin SB, Bunn PA and Byers T: Promoter hypermethylation of multiple genes in sputum precedes lung cancer incidence in a high-risk cohort. Cancer Res 66: 3338-3344, 2006.

9. Belinsky SA, Klinge DM, Dekker JD, Smith MW, Bocklage TJ, Gilliland FD, Crowell RE, Karp DD, Stidley CA and Picchi MA: Gene promoter methylation in plasma and sputum increases with lung cancer risk. Clin Cancer Res 11: 6505-6511, 2005.

10. Bhutani M, Pathak AK, Fan YH, Liu DD, Lee JJ, Tang H, Kurie JM, Morice RC, Kim ES, Hong WK and Mao L: Oral epithelium as a surrogate tissue for assessing smoking-induced molecular alterations in the lungs. Cancer Prev Res 1: 39-44, 2008.

11. Field JK, Liloglou T, Warrak S, Burger M, Becker E, Berlin K, Nimmrich I and Maier S: Methylation discriminators in NSCLC identified by a microarray based approach. Int J Oncol 27: 105-111, 2005.

12. Ehrich M, Nelson MR, Stanssens P, Zabeau M, Liloglou T, Xinarianos G, Cantor CR, Field JK and van den Boom D: Quantitative high-throughput analysis of DNA methylation patterns by base-specific cleavage and mass spectrometry. Proc Natl Acad Sci USA 102: 15785-15790, 2005.

13. Ehrich M, Field JK, Liloglou T, Xinarianos G, Oeth P, Nelson MR, Cantor CR and van den Boom D: Cytosine methylation profiles as a molecular marker in non-small cell lung cancer. Cancer Res 66: 10911-10918, 2006.

14. Kneip C,Schmidt B, Seegebarth A, Weickmann S,FleischhackerM, Liebenberg V, Field JK and Dietrich D: SHOX2 DNA methylation is a biomarker for the diagnosis of lung cancer in plasma. $J$ Thorac Oncol 6: 1632-1638, 2011.

15. Schneider KU, Dietrich D, Fleischhacker M, Leschber G, Merk J, Schäper F, Stapert HR, Vossenaar ER, Weickmann S, Liebenberg V, Kneip C, Seegebarth A, Erdogan F, Rappold G and Schmidt B: Correlation of SHOX2 gene amplification and DNA methylation in lung cancer tumors. BMC Cancer 11: 102, 2011.

16. Schmidt B, Liebenberg V, Dietrich D, Schlegel T, Kneip C, Seegebarth A, Flemming N, Seemann S, Distler J, Lewin J, Tetzner R, Weickmann S, Wille U, Liloglou T, Raji O, Walshaw M, Fleischhacker M, Witt C and Field JK: SHOX2 DNA methylation for the diagnosis of lung cancer based on bronchial aspirates. BMC Cancer 10: 600, 2010 .

17. Field JK, Smith DL, Duffy S and Cassidy A: The Liverpool Lung Project research protocol. Int J Oncol 27: 1633-1645, 2005.

18. Cottrell SE, Distler J, Goodman NS, Mooney SH, Kluth A, Olek A, Schwope I, Tetzner R, Ziebarth H and Berlin K: A real-time PCR assay for DNA-methylation using methylationspecific blockers. Nucleic Acids Res 32: e10, 2004.

19. Livak KJ and Schmittgen TD: Analysis of relative gene expression data using real-time quantitative PCR and the 2(-Delta Delta C(T)) method. Methods 25: 402-408, 2001.

20. Winer J, Jung CK, Shackel I and Williams PM: Development and validation of real-time quantitative reverse transcriptase-polymerase chain reaction for monitoring gene expression in cardiac myocytes in vitro. Anal Biochem 270: 41-49, 1999.

21. Angrill J, Agustí C, De Celis R, Filella X, Rañó A, Elena M, De La Bellacasa JP, Xaubet A and Torres A: Bronchial inflammation and colonization in patients with clinically stable bronchiectasis. Am J Respir Crit Care Med 164: 1628-1632, 2001.

22. Hill AT, Campbell EJ, Hill SL, Bayley DL and Stockley RA: Association between airway bacterial load and markers of airway inflammation in patients with stable chronic bronchitis. Am J Med 109: 288-295, 2000.

23. Ting AH, McGarvey KM and Baylin SB: The cancer epigenome - components and functional correlates. Genes Dev 20: 3215-3231, 2006.

24. Esteller M: Epigenetics in cancer. N Engl J Med 358: 1148-1159, 2008.

25. Health Protection Agency: European Directive on in vitro diagnostic medical devices (98/79/EC). National Standard Method QSOP 33 Issue 4.1. http://www.hpa-standardmethods.org.uk/ pdf_sops.asp, 2008. 